\title{
Strain-Dependent Differences in Locomotor Activity after Local Brain Irradiation with 30 GyE of Carbon Ions
}

\author{
Mayumi IWAKAWA'), Nobuhiko TAKAI'), Miyako GOTO'), \\ Shuhei NODA ${ }^{1)}$, Koichi ANDO'2), and Takashi IMAI') \\ 1)Frontier Research Center, and ${ }^{2)}$ Heavy-Ion Radiobiology Research Group, National Institute of \\ Radiological Institute, 4-9-1, Anagawa, Inage-ku, Chiba-shi 263-8555, Japan
}

\begin{abstract}
This study investigated strain differences in brain damage among male $A / J$, C57BL/6JNrs and C3H/HeNrs mice after local brain irradiation. Whole brains were irradiated with a single dose of $30 \mathrm{GyE}$ carbon ion beams and then locomotor activity was determined as body heat of each animal. The daily locomotor activities of untreated mice differed among strains. Non-irradiated C57BL/6JNrs mice were more active than A/J mice. This variance became more obvious immediately after irradiation, when the activity of $A / J$ and $\mathrm{C} 3 \mathrm{H} / \mathrm{HeNrs}$ mice diminished, whereas that of C57BL/6JNrs mice increased at the beginning of the active phase and remained elevated for three days after irradiation. The altered activities of all three strains of irradiated mice gradually recovered to normal within three to four days.
\end{abstract}

Key words: locomotor activity, radiation-induced brain damage, strain difference

The severity of normal tissue reactions after radiotherapy varies considerably among patients. Several studies have addressed individual radiosensitivity with respect to genetic factors [1-6]. However, much remains unknown about the association between genetic variation and clinical radiosensitivity. Survivors of brain malignancies of various types who undergo brain irradiation, have a risk of developing adverse effects such as brain necrosis, moyamoya syndrome, atonic seizure, behavioral changes, or metabolic disorders [7, 8]. Sato et al. described four patients who developed symptomatic radiation necrosis after CyberKnife treatment [9]. Khan et al. identified some survivors of childhood cancer who underwent cranial irradiation and then developed atonic seizures [10]. These reports suggest that normal tissue reactions vary considerably after brain irradiation. We examined the mechanism of individual radiosensitivity in murine models and gene expression analyses revealed inter-strain variations in the normal responses of the skin, lung, or intestine after irradiation $[11,12]$. The present study investigated inter-strain differences in brain damage immediately after local irradiation in $\mathrm{A} / \mathrm{J}, \mathrm{C} 57 \mathrm{BL} / 6 \mathrm{JNrs}$ and $\mathrm{C} 3 \mathrm{H} / \mathrm{HeNrs}$ mice. Many reports suggest that brain damage generally appears from several months to years after irradiation with pathological changes in brain tissue [1316]. Behavioral and histological studies of early effects are rare. Here, we measured spontaneous locomotor

(Received 17 February 2005 / Accepted 11 July 2005)

Address corresponding: M. Iwakawa, Frontier Research Center, National Institute of Radiological Institute, 4-9-1, Anagawa, Inage-ku, Chiba-shi 263-8555, Japan 


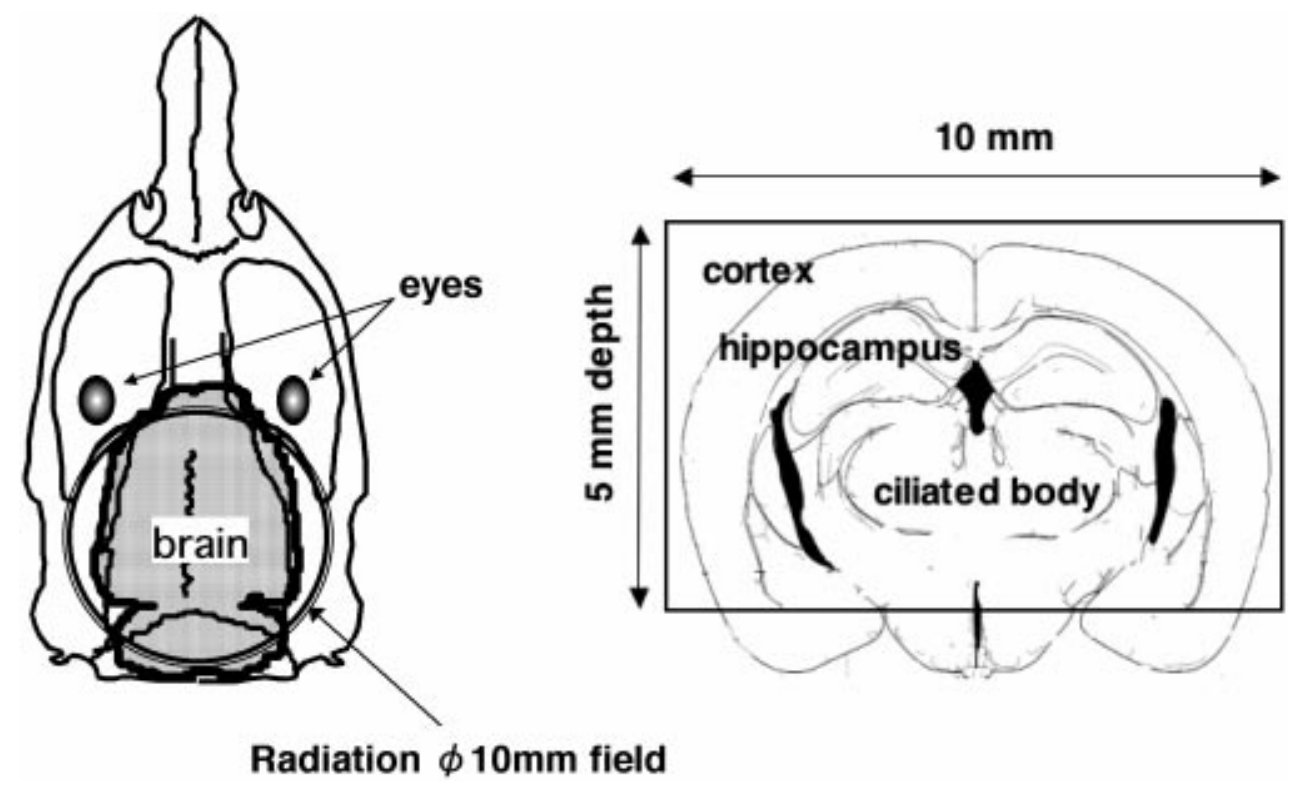

Fig. 1. Irradiation field of murine brain. Whole brain excluding the eyes and brain stem was irradiated through a circular collimator $10 \mathrm{~mm}$ in diameter under anesthesia with $50 \mathrm{mg} / \mathrm{kg}$ of pentobarbital.

activity (SLA) as a parameter of brain function in irradiated mice.

Male inbred mice of the A/J, C57BL/6JNrs and $\mathrm{C} 3 \mathrm{H} /$ HeNrs strains maintained at a specific-pathogen-free facility at the National Institute of Radiological Sciences (NIRS) were irradiated at the age of 12 weeks. A maximum of five mice were housed in cages at $22^{\circ} \mathrm{C}$ to $24^{\circ} \mathrm{C}$ under a 12 -h dark cycle (lights on from 0700 $1900 \mathrm{~h}$ ) with free access to a standard laboratory diet and water. The NIRS Institutional Animal Care and Use Committee reviewed and approved the study (protocol number 15-2018). Groups of five mice were fixed horizontally on plastic boards and irradiated with 290 $\mathrm{MeV} / \mathrm{u}$ of carbon ion beams from a 5-mm spread-out Bragg peak (SOBP) delivered from the Heavy Ion Medical Accelerator in Chiba (HIMAC) at NIRS Japan as described previously [13]. Figure 1 shows the irradiated area. The whole brain excluding the eyes and brain stem was irradiated through a circular collimator with a $10 \mathrm{~mm}$ diameter (Fig. 1). The mice were anesthetized with $50 \mathrm{mg} / \mathrm{kg}$ of pentobarbital during irradiation that was delivered at approximately midnight $(0000 \mathrm{~h})$. Non-irradiated control mice were anesthetized and underwent sham irradiation. Individual measures of locomotor activity were continuously recorded for 7 days. Locomotion scores were calculated as averages per hour over $3 \mathrm{~h}$. The system for behavioral measurements consisted of a Supermex, sound-attenuating chamber, a 64-channel interface and a personal computer with CompACT AMS software (Muromachi Kikai, Japan) [14, 15]. Spontaneous motor activities of the mice were individually measured in home cages of the Supermex system in which a sensor detects body heat.

Post hoc comparisons were applied if a significant main effect or interaction was found at $P<0.05$.

The locomotor activities of non-irradiated and irradiated $\mathrm{A} / \mathrm{J}, \mathrm{C} 57 \mathrm{BL} / 6 \mathrm{JNrs}$ and $\mathrm{C} 3 \mathrm{H} / \mathrm{HeNrs}$ mice obviously differed. Non-irradiated C57BL/6JNrs mice were more active than non-irradiated A/J mice (Fig. 2). This inter-strain variance became more obvious immediately after irradiation, as the activities of $\mathrm{A} / \mathrm{J}$ and $\mathrm{C} 3 \mathrm{H} / \mathrm{HeNrs}$ mice diminished. Figure 3 shows the effect of carbon ion irradiation on total locomotor activity per day, which was calculated by adding up all of the 30-min counts for each day. The altered activities in all three strains of irradiated mice gradually recovered within three to four days. The activities of $\mathrm{A} / \mathrm{J}$ and $\mathrm{C} 3 \mathrm{H} / \mathrm{HeNrs}$ per day were suppressed immediately after irradiation and increased thereafter. The time-dependent changes varied among the three strains. Figure 3 shows that the total activity of C57BL/6JNrs mice per day did not 

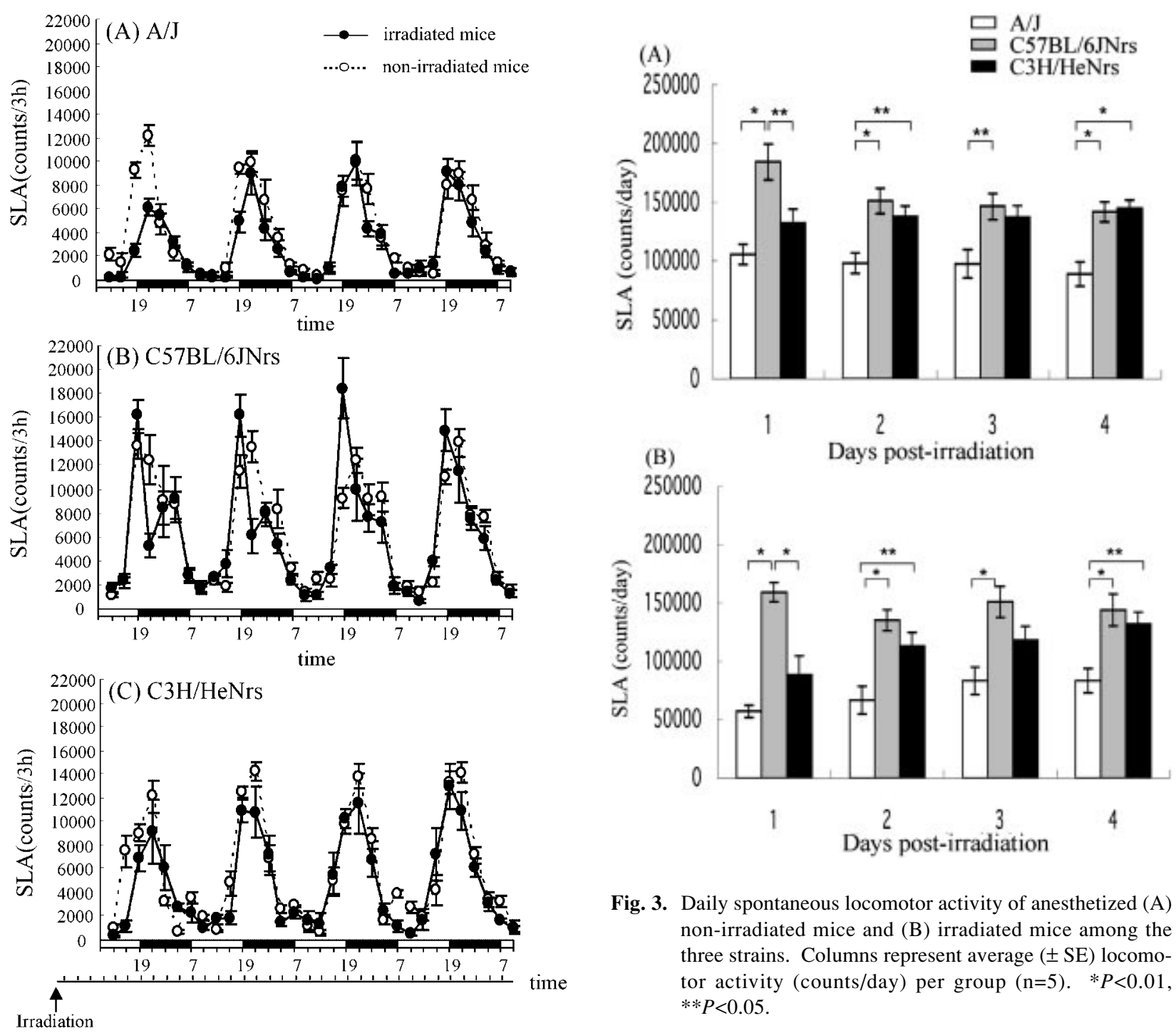

Fig. 3. Daily spontaneous locomotor activity of anesthetized (A) non-irradiated mice and (B) irradiated mice among the three strains. Columns represent average $( \pm$ SE) locomotor activity (counts/day) per group $(\mathrm{n}=5) . \quad * P<0.01$, $* * P<0.05$.

Fig. 2. Spontaneous locomotor activities among three strains of non-irradiated mice $(O)$ and mice irradiated $(\bullet)$ with 30 GyE. Each point represents average $( \pm \mathrm{SE})$ locomotor activity (counts $/ 3 \mathrm{~h}$ ) per group $(\mathrm{n}=5)$. (A) A/J mice, (B) C57BL/6JNrs mice, (C) $\mathrm{C} 3 \mathrm{H} / \mathrm{HeNrs}$ mice.

differ from that of non-irradiated C57BL/6JNrs mice, although the onset of the active and inactive phases changed within one day The activity of C57BL/6JNrs mice increased at the beginning of the active phase and this continued for three days after irradiation (Fig. 2B). The difference between irradiated and non-irradiated mice was calculated as:

Ratio of SLA counts $=$ SLA of irradiated mice $/$ SLA of non-irradiated mice.

It revealed significant inter-strain variation between

A/J and C57BL/6JNrs mice (Fig. 4).

We investigated the effects of local brain irradiation in a mouse model by monitoring SLA. Hossain and Devi investigated the effect of low dose irradiation of mice at the early fetal stage on adult brain function using locomotor activity as the indicator [20].

Several other studies have addressed inter-strain differences in brain function. Correa et al. compared motor behavior and enzymatic changes in the brains of outbred Swiss or CD1, and inbred BALB/c, C57BL/J6 or DBA/2 mice after acute lead intoxication [21]. None of the strains differed after exposure to saline or lead. However, strain-dependent differences were evident in sham-treated mice of several strains such as in forced swimming and tail stretching responses. Yoshikawa 


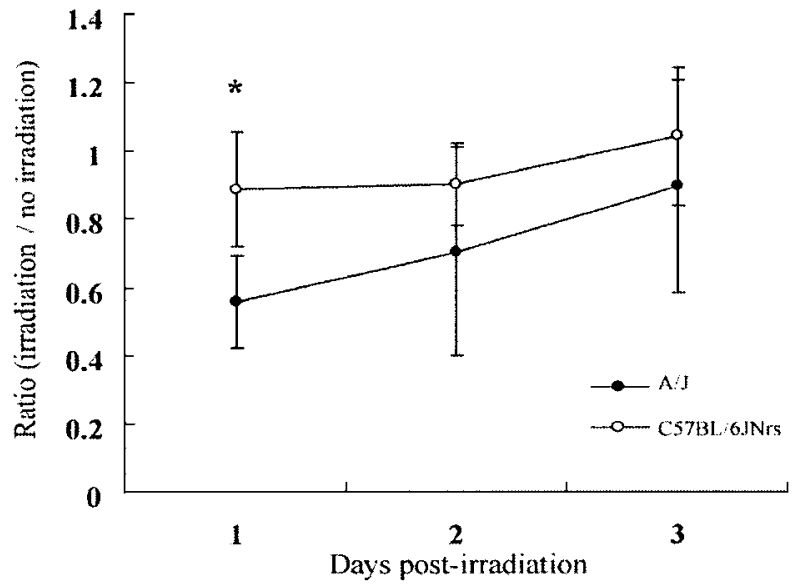

Fig. 4. Time-dependent changes of ratio of SLA counts. Ratio of SLA counts = SLA of irradiated mice $/$ SLA of nonirradiated mice. $* P<0.05$.

identified multiple genetic loci linked to the propensity for behavioral despair in mice [22]. To identify genetic determinants of the duration of immobility in the forced swim and tail suspension tests, they analyzed F2 mice from an intercross between $\mathrm{C} 57 \mathrm{BL} / 6$ and $\mathrm{C} 3 \mathrm{H} / \mathrm{He}$ strains. The QTL (quantitative trait linkage) analysis revealed gamma-aminobutyric acid type A receptor subunits and expression analysis of this gene displayed significantly lower expression of the alpha1 subunit gene in the frontal cortex of C57BL/6, compared with $\mathrm{C} 3 \mathrm{H} / \mathrm{He}$ mice. Such qualitative and quantitative analyses of physiological variations in mouse models might help to identify genetic factors associated with human brain damage after irradiation.

In conclusion, the early response of the brain determined as locomotor activity varied in three strains of locally irradiated mice. Complex biological pathways that are affected by strain-dependent factors appear to be involved in strain-dependent physiology of the brain during radiation-induced early damage and recovery.

\section{Acknowledgments}

The authors thank Katsutaka Oishi, Ph. D for helpful discussion. We wish to express our deep thanks to Mr. Tatsuo Hayao and Mrs. Yuriko Ogawa for their animal-care services. Mrs. Etsuko Hagiwara is gratefully acknowledged for graphical assistance.

\section{References}

1. Andreassen, C.N., Alsner, J., and Overgaard, J. 2002. Radiother. Oncol. 64: 131-140.

2. Alter, B.P. 2002. Radiother. Oncol. 62: 345-347.

3. Barber, J.B., Burrill, W., Spreadborough, A.R., Levine, E., Warren, C., Kiltie, A.E., Roberts, S.A., and Scott, D. 2000. Radiother. Oncol. 55: 179-186.

4. Gatti, R.A. 2001. Acta. Oncol. 40: 702-711.

5. Hu, J.J., Smith, T.R., Miller, M.S., Mohrenweiser, H.W., Golden, A., and Case, L.D. 2001. Carcinogenesis 22: 917922.

6. Leong, T., Whitty, J., Keilar, M., Mifsud, S., Ramsay, J., Birrell, G., Venter, D., Southey, M., and McKay, M. 2000. Int. J. Radiat. Oncol. Biol. Phys. 48: 959-965.

7. Kondoh, T., Morishita, A., Kamei M., Okamura, Y., Tamaki, M., and Kohmura, E. 2003. Pediatr. Neurosurg. 39: 264-269.

8. Nosov, A.V., Ivnitsky, Y.Y., and Malakhovsky. V.N. 1999. Radiat. Res. 152: 523-529.

9. Sato, K., Baba, Y., Inoue, M., and Omori, R. 2003. Acta. Neurochir Suppl. 86: 513-517.

10. Khan, R., Marshman, B.K.C., and Mulhern, R.K. 2003. J. Child Neurol. 18: 397-400.

11. Iwakawa, M., Noda, S., Ohta, T., Ohira, C., Lee, R., Goto, M., Wakabayashi, M., Matsui, Y., Harada, Y., and Imai. T. 2003. J. Radiat. Res. 44: 7-13.

12. Iwakawa, M., Noda, S., Ohta, T., Oohira, C., Tanaka, H., Tsuji, A., Ishikawa, A., and Imai, T. 2004. J. Radiat. Res. 45: 423-433.

13. Calvo, W., Hopewell, J., Reinhold, H., and Yeung, T. 1988. Br. J. Radiol. 61: 1043-1052.

14. Hodges, H., Katzung, N., Sowinski, P., Hopewell, J., Wilkinson, J., Bywaters, T., and Rezvani, M. 1998. Behav. Brain. Res. 91: 99-114.

15. Lamproglou, I., Chen, Q., Boisserie, G., Mazeron, J., Poisson, M., Baillet, F., Le Poncin, M., and Delattre, J. 1995. Int. J. Radiat. Oncol. Biol. Phys. 31: 65-70.

16. Yoneoka, Y., Satoh, M., Akiyama, K., Sano, K., Fujii, Y., and Tanaka, R. 1999. Br. J. Radiol. 72: 1196-1201.

17. Takahashi, S., Sun, X. Z., Kubota, Y., Takai, N., and Nojima, K. 2002. J. Radiat. Res. 43: 143-152.

18. Ishidi, M., Masuo, Y., Oka, S., and Kumimoto, M. 2002. J. Health Science 48: 451-454.

19. Masuo, Y., Matsumoto, Y., Morita, S., and Noguchi, J. 1997. Brain Res. Protoc. 1: 321-326.

20. Hossain, M. and Uma Devi, P. 2000. Int. J. Radiat. Biol. 76: 1397-1402.

21. Correa, M., Roig- Navarro, A.F., and Aragon. C.M. 2004. Life Sci. 74: 2009-2021.

22. Yoshikawa, T., Watanabe, A., Ishitsuka, Y., Nakaya, A., and Nakatani, N. 2002. Genome Res. 12: 357-366. 